Jurnal Sulolipu : Media Komunikasi Sivitas Akademika dan Masyarakat

Vol. 19 No.12019

e-issn : 2622-6960, p-issn : 0854-624X

\title{
PERILAKU PENGRAJIN MEUBEL DALAM PENGGUNAAN ALAT PELINDUNG DIRI (APD) DI KELURAHAN MANONGKOKI KECAMATAN POLONGBANGKENG UTARA KABUPATEN TAKALAR \\ Siti Ardianti Arsyad ${ }^{1}$ dan Abdur Rivai ${ }^{2}$ \\ 1.2 Jurusan Kesehatan Lingkungan Poltekkes Kemenkes Makassar \\ abdur.rivai@yahoo.com
}

\section{ABSTRACT}

Along with the growth and rapid industrial development has driven the increasing use of machinery, equipment, and chemicals in the production process, accompanied by the application of techniques and technology of various levels and in all sectors of activity. The purpose of this research is to determine the behavior of furniture craftsmen to the use of protective equipment in the Village series Manongkoki District of North Polongbangkeng Takalar. This type of research is observational with a descriptive approach, which is a survey on furniture craftsman to see a picture that occurs in a given population. The results showed that $20.83 \%$ of knowledge workers very well, $48.61 \%$ and $30.56 \%$ good knowledge knowledgeable pretty good. There are $40.3 \%$ of attitude is very good, $50 \%$ good attitude and as much as $9.7 \%$ is a pretty good attitude. There is $41.67 \%$ for an action that has very good action, a good action by $34.72 \%$ and $23.61 \%$ who have pretty good action.

Keywords: Knowledge, Attitude, Action, Personal Protective Equipment

\section{ABSTRAK}

Seiring dengan pertumbuhan dan perkembangan industri yang begitu pesat telah mendorong semakin meningkatnya penggunaan mesin, peralatan kerja dan bahan-bahan kimia dalam proses produksi dengan disertai penerapan teknik dan teknologi dari berbagai tingkat di segenap sektor kegiatan. Tujuan dalam penelitian ini yaitu untuk mengetahui perilaku pengrajin meubel terhadap penggunaan alat pelindung siri di Kelurahan Manongkoki Kecamatan Polongbangkeng Utara Kabupaten Takalar. Jenis penelitian ini adalah observasi dengan pendekatan deskriftif, yaitu suatu survey pada pengrajin meubel untuk melihat gambaran yang terjadi di dalam suatu populasi tertentu. Hasil penelitian menunjukkan bahwa $20.83 \%$ pekerja yang berpengetahuan sangat baik , $48.61 \%$ berpengetahuan baik dan $30.56 \%$ yang berpengetahuan cukup. Untuk sikap terdapat $40.30 \%$ sikap sangat baik , 50.00\% sikap baik dan sebanyak $9.70 \%$ sikap cukup. Untuk tindakan terdapat $41.67 \%$ yang memiliki tindakan sangat baik, $34.72 \%$ tindakan baik dan $23.61 \%$ yang memiliki tindakan cukup.

Kata kunci : Pengetahuan, Sikap, Tindakan, Alat Pelindung Diri

\section{PENDAHULUAN}

Seiring dengan pertumbuhan dan perkembangan industri yang begitu pesat telah mendorong semakin meningkatnya penggunaan mesin, peralatan kerja dan bahan-bahan kimia dalam proses produksi dengan disertai penerapan teknik dan teknologi dari berbagai tingkat disegenap sector kegiatan. Hal ini berarti pula dapat menimbulkan resiko kecelakaan akibat kerja yang lebih tinggi dan juga terjadi peningkatan jumlah intensitas sumber bahaya di tempat kerja (Suma'mur, 1996 dalam wulansari 2009).

Keselamatan dan kesehatan kerja harus benar-benar diterapkan dalam suatu perusahaan, pengawasan tidak hanya terhadap mesin saja tetapi yang lebih penting terhadap manusianya. Hal ini dilakukan karena manusia adalah faktor yang paling penting dalam suatu proses. Tindakan keselamatan kerja bertujuan untuk menjamin keutuhan dan kesempurnaan, baik jasmani maupun rohan manusia, serta hasil kerja dan budaya tertuju pada kesejahteraan masyarakat pada umumnya (Daryanto, 2010).

Keselamatan pekerja merupakan faktor yang sangat dominan dalam suatu industry, karena majunya suatu industry sangatlah pula adanya suatu jaminan keselamatan pada pekerja. Jadi hal tersebut merupakan kunci lancarnya suatu produktivitas dan suatu perusahaan. Keselamatan kerja adalah keselamatan yang berkaitan dengan mesin, pesawat, alat kerja, bahan, proses pengolahannyalandasan tempat kerja, dan lingkungannya, serta cara-cara melakukan pekerjaan. Keselamatan kerja bersasaran segala tempat kerja baik di darat, di dalam tanah, dipermukaan air, di dalam air, maupun di udara (Suma'mur, 1996 dalam wulansari 2009).

Dasar hukum sistem keselamatan dan kesehatan kerja (K3) tercantum dalam undangundang keselamatan No. 1 tahun 1970 tentang keselamatan kerja. Dalam undang.-undang No. 23 tahun 1992 tentang kesehatan, pasal 23 dinyatakan bahwa K3 harus diselenggarakan semua ditempat kerja, khususnyaa tempat kerja yang mempunyai resiko bahaya kesehatan, mudah terjangkit penyakit atau mempunyai karyawan paling sedikit sepuluh orang.

\section{METODE PENELITIAN}

\section{Lokasi Penelitian}

Lokasi penelitian ini dilakukan di Kelurahan Manongkoki Kecamatan Polongbangkeng Utara Kabupaten Takalar pada karyawan pengrajin meubel.

\section{Variable Penelitian}

Variabel bebas dalam penelitian ini adalah Perilaku yang terdiri atas 
Pengetahuan, Sikap, dan Tindakan pada pekerja pengrajin meubel. Variabel terikat dalam penelitian ini adalah penggunaan APD, yang meliputi kepala, mata dan muka, telinga, pernapasan, tangan, dan kaki. Variabel pengganggu dalam penelitian ini adalah lama masa kerja dan umur, dalam hal ini tidak diteliti.

\section{Defenisi Operasional}

a) Alat Pelindung Diri adalah alat yang digunakan oleh pekerja meubel untuk mencegah atau mengurangi terjadinya kecelakaan kerja di Kelurahan Manongkoki Kecamatan Polongbangkeng Utara Kabupaten Takalar.

b) Pengetahuan yang dimaksud dalam penelitian ini adalah yang diketahui oleh pekerja meubel tentang bagaimana cara penggunaan APD dalam bekerja di Kelurahan Manongkoki Kecamatan Polongbangkeng Utara Kabupaten Takalar.

c) Sikap yang dimaksud dalam penelitian ini adalah respon baik dari pekerja meubel mengunakan APD dalam bekerja di Kelurahan Manongkoki Kecamatan Polongbangkeng Utara Kabupaten Takalar.

d) Tindakan yang dimaksud dalam penelitian ini adalah perlakuan atau aktivitas pekerja dalam menggunakan APD pada saat bekerja di Kelurahan Manongkoki Kecamatan Polongbangkeng Utara Kabupaten Takalar.

\section{Krireria Objektif}

a. Alat Pelindung Diri (APD) : Alat yang digunakan untuk melindungi diri dari kecelakaan kerja.

1) Sangat baik : Apabila Responden Menjawab dengan Skor $>80-100 \%$ Dari Pertanyaan Tentang Alat Pelindung Diri.

2) Baik : Apabila Responden Menjawab dengan Skor >60$79,99 \%$ Dari Pertanyaan Tentang Alat Pelindung Diri.

3) Cukup : Apabila Responden Menjawab dengan Skor >40$59,99 \%$ Dari Pertanyaan Tentang Alat Pelindung Diri.

b. Pengetahuan Adalah: Segala apa yang diketahui oleh responden terhadap suatu obyek tentang pekerja meubel pada penggunaan alat pelindung diri dalam bekerja
1) Sangat baik : Apabila Responden Menjawab dengan Skor $>80-100 \%$ Dari Pertanyaan Tentang Pengetahuan.

2) Baik : Apabila Responden Menjawab dengan Skor >6079,99\% Dari Pertanyaan Tentang Alat Pelindung Pengetahuan.

3) Cukup : Apabila Responden Menjawab dengan Skor $>40$ 59,99\% Dari Pertanyaan Tentang Pengetahuan.

c. Sikap Adalah: tanggapan terhadap pekerja meubel pada penggunaan alat pelindung diri dalam bekerja.

1) Sangat baik : Apabila Responden Menjawab dengan Skor $>80-100 \%$ Dari Pertanyaan Tentang Sikap.

2) Baik : Apabila Responden Menjawab dengan Skor >60$79,99 \%$ Dari Pertanyaan Tentang Sikap.

3) Cukup : Apabila Responden Menjawab dengan Skor >4059,99\% Dari Pertanyaan Tentang Sikap.

d. Tindakan Adalah: perlakuan, atau aktivitas pekerja meubel terhadap penggunaan alat pelindung diri dalam bekerja.

1) Sangat baik : Apabila Responden

Menjawab dengan Skor >80100\% Dari Pertanyaan Tentang Tindakan.

2) Baik : Apabila Responden Menjawab dengan Skor >60$79,99 \% \quad$ Dari Pertanyaan Tentang Tindakan.

3) Cukup : Apabila Responden Menjawab dengan Skor >4059,99\% Dari Pertanyaan Tentang Tindakan.

\section{Sampel}

Sampel dalam penelitian ini adalah pengrajin meubel sebanyak 72 pekerja/karyawan yang terdiri dari 9 pekerja dari setiap home industri yang berjumlah 8 di Kelurahan Manongkoki Kecamatan Polongbangkeng Utara Kabupaten Takalar, dengan teknik pengambilan sampel dilakukan dengan menggunakan total sampling (keseluruhan populasi yang berjumlah 72 pekerja/karyawan).

\section{TEKNIK PENGAMBILAN DATA}

\section{Data Primer}

Data primer adalah data yang diperoleh dari hasil obsevasi dan wawancara langsung 
Jurnal Sulolipu : Media Komunikasi Sivitas Akademika dan Masyarakat

Vol. 19 No.12019

e-issn : 2622-6960, p-issn : 0854-624X

dengan menggunakan kuisioner terhadap objek sasaran yaitu responden.

\section{Data Sekunder}

Data sekunder adalah data yang diperoleh dari panduan buku, jurnal dan literature / bacaan skripsi, internet, pdf yang di anggap berhubungan dengan penelitian ini.

\section{Pengolahan Data dan Analisa Data}

Data yang diperoleh dari hasil Observasi disajikan dalam bentuk tabel, diolah secara manual dan komputer serta di analisa secara deskriptif.

\section{HASIL PENELITIAN DAN PEMBAHASAN}

1. Hasil Penelitian

a. Distribusi umur responden Tabel 1

Distribusi pekerja/karyawan berdasarkan umur

b. Distribusi pendidikan responden

Tabel 2

Distribusi pekerja/karyawan berdasarkan pendidikan

\begin{tabular}{cccc}
\hline No & Pendidikan & Frek & $\%$ \\
\hline $\mathbf{1}$ & Tidak tamat SD & 8 & 11.11 \\
\hline $\mathbf{2}$ & SD & 19 & 26.39 \\
\hline $\mathbf{3}$ & SMP & 17 & 23.61 \\
\hline $\mathbf{4}$ & SMA & 28 & 38.89 \\
\hline $\mathbf{5}$ & Perguruan tinggi & 0 & 0 \\
\hline & Total & 72 & 100 \\
\hline
\end{tabular}

Sumber : Data Primer 2018

\section{c. Distribusi masa kerja responden}

Tabel 3

Distribusi pekerja/karyawan berdasarkan masa kerja

\begin{tabular}{cccc}
\hline No & Pendidikan & Frekuensi & $\%$ \\
\hline $\mathbf{1}$ & $\begin{array}{c}1-11 \\
\text { bulan }\end{array}$ & 5 & 6.94 \\
\hline $\mathbf{2}$ & $1-5$ tahun & 33 & 45.83 \\
\hline $\mathbf{3}$ & $\begin{array}{c}6-10 \\
\text { tahun }\end{array}$ & 27 & 37.50 \\
\hline $\mathbf{4}$ & $\begin{array}{c}11-15 \\
\text { tahun }\end{array}$ & 4 & 5.56 \\
\hline $\mathbf{5}$ & $\begin{array}{c}16-20 \\
\text { tahun }\end{array}$ & 3 & 4.17 \\
\hline & Total & 72 & 100 \\
\hline
\end{tabular}

Sumber : Data Primer 2018

\section{d. Penggunaan Alat Pelindung Diri} (APD)

Tabel 4

Penggunaan Alat pelindung Diri (hasil observasi pengamatan langsung) \begin{tabular}{lll}
\hline No & Penggunaan APD & Frek $\%$
\end{tabular}

\begin{tabular}{cccc}
\hline 1 & $\begin{array}{c}\text { Sangat baik } \\
\text { (memakai) }\end{array}$ & 5 & 6.94 \\
\hline 2 & $\begin{array}{c}\text { Baik (kadang- } \\
\text { kadang) }\end{array}$ & 33 & 45.83 \\
\hline 3 & $\begin{array}{c}\text { Cukup (tidak } \\
\text { memakai) }\end{array}$ & 27 & 37.50 \\
\hline & Total & 72 & 100 \\
\hline
\end{tabular}

Sumber : Data Primer 2018

\section{e. Pengetahuan}

Tabel 5

Distribusi pekerja/karyawan berdasarkan pengetahuan terhadap penggunaan APD

$\begin{array}{llll}\text { No } & \text { Pengetahuan } & \text { Frek } & \end{array}$

\begin{tabular}{cccc}
\hline $\mathbf{1}$ & Sangat baik & 15 & 20.83 \\
\hline $\mathbf{2}$ & Baik & 35 & 48.61 \\
\hline $\mathbf{3}$ & Cukup & 22 & 30.56 \\
\hline & Total & 72 & 100 \\
\hline
\end{tabular}

Sumber : Data Primer 2018 
Jurnal Sulolipu : Media Komunikasi Sivitas Akademika dan Masyarakat

Vol. 19 No. 12019

e-issn : 2622-6960, p-issn : 0854-624X

\section{f. Sikap}

Tabel 6

Distribusi pekerja/karyawan berdasarkan sikap terhadap penggunaan APD

\begin{tabular}{cccc}
\hline No & Sikap & Frek & $\%$ \\
\hline 1 & Sangat baik & 29 & 40.3 \\
\hline 2 & Baik & 36 & 50 \\
\hline 3 & Cukup & 7 & 9.7 \\
\hline & Total & 72 & 100 \\
\hline
\end{tabular}

Sumber : Data Primer 2018

g. Tindakan

Tabel 7

Distribusi pekerja/karyawan berdasarkan tindakan terhadap penggunaan APD

\begin{tabular}{cccc}
\hline No & Tindakan & Frek & $\%$ \\
\hline $\mathbf{1}$ & $\begin{array}{c}\text { Sangat } \\
\text { baik }\end{array}$ & 30 & 41.67 \\
\hline $\mathbf{2}$ & Baik & 25 & 34.72 \\
\hline $\mathbf{3}$ & Cukup & 17 & 23.61 \\
\hline & Total & 72 & 100 \\
\hline
\end{tabular}

Sumber : Data Primer 2018

2. Pembahasan

a. Pengetahuan Pengrajin Meubel Terhadap Penggunaan Alat Pelindung Diri di Kelurahan Manongkoki Kecamatan Polongbangkeng Utara Kabupaten Takalar. Berdasarkan hasil tingkat pengetahuan yang diperoleh dari 72 pekerja/karyawan pengrajin meubel, menunjukan bahwa tingkat pengetahuan sangat baik sebanyak 15 orang $(20.83 \%)$, baik 35 orang (48.61\%) dan yang cukup 22 orang $(30.56 \%)$.

Pengetahuan merupakan bagian pertama yang harus diperhatikan, karena pengetahuan memegang peranan penting didalam menentukan cara penggunaan alat pelindung diri yang baik. Pengetahuan Pengrajin meubel adalah pengetahuan tentang bagaimana menggunakan APD yang memenuhi syarat untuk para pekerja pengrajin meubel.

Berdasarkan wawancara langsung yang dilakukan terhadap 72 responden menunjukkan bahwa tingkat pengetahuan cukup sebanyak 22 orang (30.56\%), di karenakan dari segi pendidikan rendah, dan tidak mengetahui apa itu pelindung diri,sedangkan yang berpengetahun sangat baik yang tidak memakain alat pelindung diri beralasan karena faktor kenyamanan saat bekerja dan merasa tidak bebas bergerak saat menggunakan APD. Adapula karyawan yang berasalan bahwa tempat bekerjanya tidak beresiko dan kurangnya kesadaran perajin dalam menggunakan APD pada saat bekerja.

Dan kurangnya penyebaran informasi melalui penyuluhan yang dilakukan secara rutin dan baik dengan pendekatan perorangan ataupun secara berkelompok sehingga pengetahuan pengerajin meubel di Kelurahan Manongkoki Kecamatan Polongbangkeng utara tentang kesehatan cara penggunaan alat pelindung diri yang baik.

Sebagaimana diketahui bahwa Keselamatan dan kesehatan kerja adalah suatu pemikiran dan upaya untuk menjamin keutuhan dan kesempurnaan baik jasmani maupun rohaniah tenaga kerja pada khususnya, dan manusia pada umumnya, hasil karya dan budaya untuk menuju masyarakat adil dan makmur (Sri Rejeki, 2015). Sehingga meskipun pengetahuan pekerja ada pada kategori tinggi, namun ada beberapa hal yang masih perlu diperhatikan dan dicermati, baik itu oleh perusahaan maupun oleh pekerja itu sendiri yaitu mengenai pemakaian alat pelindung diri pada saat bekerja

b. Sikap Pengrajin Meubel Terhadap Penggunaan Alat Pelindung Diri di Kelurahan Manongkoki Kecamatan Polongbangkeng Utara Kabupaten Takalar.

Berdasarkan hasil sikap responden yang diperoleh dari 72 pekerja/karyawan pengrajin meubel, menunjukan bahwa sikap responden sangat baik sebanyak 29 orang $(40.3 \%)$, baik 36 orang $(50 \%)$ dan yang cukup 7 orang $(9.7 \%)$.

Menurut Newcomb dalam Notoatmodjo (2003), sikap merupakan kesiapan atau kesediaan untuk bertindak, yang menjadi predisposisi tindakan suatu perilaku, bukan pelaksanaan motif tertentu. Sikap merupakan kesiapan untuk bereaksi terhadap objek dilingkungan tertentu suatu penghayatan terhada objek (Heri D.J. 2009).

Dari hasil tersebut dapat diketahui bahwa pekerja yang memiliki sikap yang cukup baik 7 orang $(9.7 \%)$, karena dimana kebanyakan pengrajin meubel tidak mementingkan kesehatannya sendiri sehingga banyak yang peduli terhadap penggunaan alat pelindung diri (APD), dan dimana pengrajin meubel ini juga dipengaruhi oleh pengetahuan yang cukup, karena kurangnya bimbingan dan penyuluhan sehingga sikap mental 
Jurnal Sulolipu : Media Komunikasi Sivitas Akademika dan Masyarakat

Vol. 19 No.12019

e-issn : 2622-6960, p-issn : 0854-624X

kesadaran pribadi sendiri pada pekerja pengrajin meubel.

Pekerja pengrajin meubel tidak mengetahui dampak yang ditimbulkan serta penyakit akibat kerja yang dapat terjadi. Dimana penyakit kerja merupakan merupakan kondisi abnormal atau penyakit yang disebabkan oleh kerentanan terhadap faktor lingkungan yang terkait dengan pekerjaan. Hal ini meliputi penyakit akut dan kronis yang disebebkan oleh pernafasan, penyerapan, pencemaran, atau kontak langsung dengan alat-alat kerja yang dapat memicu adanya penyakit kerja.

Sikap terhadap penggunaan APD yang kurang baik disebabkan oleh beberapa faktor seperti kenyamanan yang dirasakan apabila APD dapat mengganggu aktivitas saat melakukan pekerjaan. Kenyamanan karyawan saat bekerja dapat mempengaruhi konsentrasi sehingga produktivitas pekerja menurun dan dapat menyebabkan kerugian pada karyawan maupun industri tersebut.

Kebiasaan menganggap remeh bahwa menggunakan APD tidak terlalu penting justru akan mengakibatkan dampak buruk bagi keselamatan pengrajin meubel, sehingga perlu dilakukan upaya untuk mengubah sikap agar tercipta tindakan yang benar dalam melakukan pekerjaan.

c. Tindakan pekerja Pengrajin Meubel Terhadap Penggunaan Alat Pelindung Diri di Kelurahan Manongkoki Kecamatan Polongbangkeng Utara Kabupaten Takalar.

Berdasarkan tindakan responden terhadap penggunaan APD yang diperoleh dari 72 pekerja/karyawan pengrajin meubel, menunjukan bahwa tindakan sangat baik sebanyak 30 orang $(41.67 \%)$, baik 25 orang $(34.72 \%)$ dan yang cukup 17 orang (23.61\%).

Tindakan adalah Suatu sikap belum otomatis terwujud dalam suatu tindakan (overt behaviuor). Untuk mewujudkan sikap menjadi suatu perbuatan nyata diperlukan factor pendukung atau suatu kondisi yang memungkinkan, antara lain adalah fasilitas..

Dilihat dari teori diatas, sesuai dengan tindakan pekerja yang masih berupa sikap dan belum ada tindakan secara nyata karena kurangnya pengetahuan melalui penyuluhan dan pendidikan (SMP-SMA) yang dapat memicu tindakan terhadap menggunakan alat pelindung diri (APD). Hal ini dapat memicu kecelakaan kerja dan penyakit kerja kerena mereka ada yang mengetahui dan tidak mengetahui tentang alat pelindung diri (APD) tetapi tidak sejalan dengan aturan Alat pelindung Diri untuk
Pengrajin Meubel sehingga apa yang mereka lakukan untuk menjaga keselamatan terhadap dirinya.

d. Penggunaan alat pelindung diri (APD) pada pekerja pengrajin meubel di Kelurahan Manongkoki Kecamatan Polongbangkeng Utara Kabupaten Takalar.

Berdasarkan hasil yang telah diperoleh, Dari data di atas dapat diketahui bahwa 72 responden atau pekerja/karyawan pengrajin meubel yang tidak memakai APD yaitu 47 orang $(65,28 \%), 25$ orang $(34,72 \%)$ yang kadang-kadang memakai APD dan yang memakai APD 0 orang $(0 \%)$. Alat pelindung diri sesuai yang dibutuhkan di tempat kerja seperti helmet, sarung tangan, sepatu, masker, pelindung telinga atau ear plug serta pakaian pelindung atau pakaian kerja.

Hasil wawancara yang telah
dilakukan sebagian pekerja tidak menggunakan alat pelindung diri 47 orang $(65,28 \%)$, disebabkan karena alasan kurang nyaman, merasa risih karena tidak terbiasa memakainya, dan beralasan tidak memiliki karena faktor ekonomi dan tidak pernah memperhatiakn tentang pentingnya alat pelindung diri pada saat bekerja, meskipun jarang dilakukan penyuluhan tentang penggunaan alat pelindung diri (APD), adapun 25 orang $(34,72 \%)$ yang kadangkadang mamakai APD dengan alasan hanya memiliki satu alat pelindung seperti masker, helmet, pelindung kaki/sepatu, dan pelindung tangan, bahkan tidak ada yang memiliki pelindung telinga dan disebabkan juga kurangnya pengetahuan melalui penyuluhan yang dapat memicu pentingnya penggunaan alat pelindung diri (APD, pekerja pengrajin meubel juga yakin bahwa tanpa alat pelindung diri (APD) akan tetap aman, hal tersebut karena beranggapan bahwa apa yang akan dilakukannya aman dan tidak menimbulkan resiko kecelakan, akibat perilaku sebelumnya, dimana saat tidak menggunakan alat pelindung diri (APD) ternyata aman, jadi hal tersebut membuat pekerja berasumsi bahwa saat ini juga pasti aman seperti sebelumnya.

Dari hal tersebut diharapkan adanya motivasi atau dorongan diri pemerintah dan kesadaran pekerja terhadap penggunaan alat pelindung diri (APD) agar terhindar dari kecelakaan dan penyakit akibat kerja yang dapat membahayakan bagi pekerja.

Dari hasil penelitian oleh zulkifli (2013) tentang Hubungan pengetahuan dan sikap pekerja terhadap penggunaan alat 
pelindung diri (APD) di Industri Sermani Stell Makassar, dari 120 responden yang tidak memakai alat pelindung diri (APD) sebanyak $73(61 \%)$ dan memakai alat pelindung diri (APD) sebanyak 47 (39\%). Sedangkan pengetahuan responden terhadap penggunaan alat pelindung diri (APD) yang dikategorikan tinggi sebanyak $108(90 \%)$, sedang $12(10 \%)$, rendah $0(0 \%)$, dan sikap responden terhadap penggunaan alat pelindung diri yang dikategorikan tinggi sebanyak $101(84,17 \%)$, sedang $19(15,83 \%)$, rendah $0(0 \%)$ responden.

$\mathrm{Hal}$ ini sejalan dengan penelitian Ayyub (2014) tentang hubungan pengetahuan, sikap, dan tindakan tenaga kerja dengan pemakaian alat pelindung diri (apd) di pt. sermani steel corporation Makassar bahwa ada hubungan antara pengetauan, sikap, dan tindakan terhadap penggunaan alat pelindung diri. pada saat melaksanakan pekerjaan, sebagian besar karyawan tidak tergolong dalam tingkat tindakan pekerja saat bekerja telah menggunakan. Sehingga kesadaran dari para pekerja itu sendiri perlu ditingkatkan untuk meminimalisir atau mengurangi tingkat kecelakaan akibat kerja terhadap karyawan yang kurang memperhatikan penggunaan alat pelindung diri.

Penelitian sejenis juga dilakukan oleh peneliti Nurul Imran 2014 tentang Studi Perilaku Alat Pelindung Diri pada pekerja batu Nisan di Desa Lempang Kecamatan Tanete Riaja Kabupaten Barru, dari 90 responden yang tidak memamkai alat pelindung diri (APD) sebanyak $42(46,7 \%)$ dan memakai alat pelidung diri (APD) sebanyak $48 \quad(53,3 \%)$. Sedangkan pengetahuan responden terhadap alat pelindung diri (APD) yang dikategorikan tinggi sebanyak $81(90 \%)$, sedang $8(8,9 \%)$, rendah $1(1,1 \%)$, dan sikap responden terhadap alat pelindung diri (APD) yang dikategorikan tinggi sebanyak $46(51,1 \%)$, sedang $43(47,8 \%)$, rendah $1(1,1 \%)$, dan tindakan terhadap penggunaan alat pelindung diri (APD) yang dikategorikan tinggi sebanyak $43(47,8 \%)$, sedang 24 $(26,7 \%)$, dan rendah $23(25,5 \%)$ responden.

Menurut penelitian yang dilakukan

Lukman Hakim ( 2004 dalam Andi Nurhusna), pekerja yang tidak menggunakan APD sebanyak $58,5 \%$ disebabkan karena ketidak tersediaan APD dan pengawasan yang kurang. Menurut penelitian yang dilakukan Susanto ( 2005 ), pengetahuan tentang alat pelindung diri $50 \%$ kurang baik dikarenakan dari segi pendidikan yang rendah dan tidak pernah mengetahui apa itu alat pelindung diri.

Demikian pula halnya dengan sikap yaitu $63,2 \%$ (43 orang) menunjukkan sikap positif terhadap penggunaan APD. Namun ternyata hanya $45,6 \% \quad(31 \%)$ yang mempraktikkan penggunaan APD saat melakukan pekerjaan.

\section{Kesimpulan}

Berdasarkan hasil analisa dan pembahasan tentang peilaku terhadap penggunaan alat pelindung diri pada pengrajin meubel di Kelurahan Manongkoki kecamatan polongbangkeng utara kabupaten takalar, maka dapt disimpulkan bahwa :

a. Tingkat pengetahuan pengrajin meubel di kategorikan sangat baik sebanyak 15 orang (20.83\%), kategori baik 35 orang $(48.61 \%)$ dan kategori cukup 22 orang (30.56\%) terhadap penggunaan alat pelindung diri pada pekerja pengrajin meubel di Kelurahan Manongkoki Kecamatan Polongbangkeng Utara Kabupaten Takalar.

b. Sikap pekerja yang di kategorikan sangat baik sebanyak 29 orang $(40.3 \%)$, kategori baik 36 orang $(50 \%)$ dan kategori cukup 7 orang $(9.7 \%)$ terhadap penggunaan alat pelindung diri pada pekerja pengrajin meubel di Kelurahan Manongkoki Kecamatan Polongbangkeng Utara Kabupaten Takalar.

c. Kategori tindakan sangat baik sebanyak 30 orang (41.67\%),kategori baik 25 orang (34.72\%) dan kategori cukup baik 17 orang $(23.61 \%)$ pada pekerja pengrajin meubel.

\section{Saran}

Berdasarkan kesimpulan yang telah dijelaskan sbelumnya, maka saran yang diajukan pada penelitian ini :

1. Perlu adanya pengawasan dari pihak pemerintah setempat, agar pekerja sadar untuk menggunakan alat pelindung diri pada peekerja pengrajin meubel.

2. Dilaksanakan penyuluhan akan pentingnya penggunaan alat pelindung diri pada pekerja/karyawan yang mempunyai risiko kecelakaan kerja sehingga dapat ditekan seminimal mungkin.

3. Perlu meningkatkan penegakan disiplin kerja terhadap penggunaan alat pelindung diri dengan melakukan teguran dan sanksi kepada pekerja/karyawan pengrajin meubel yang melanggar serta perlu adanya keteladanan dari pemerintah setempat agar memperhatikan penggunaan alat pelindung diri pada pekerja pengrajin meubel 
Jurnal Sulolipu : Media Komunikasi Sivitas Akademika dan Masyarakat

Vol. 19 No.12019

e-issn : 2622-6960, p-issn : 0854-624X

4. Untuk peneliti selanjutnya agar dapat memperdalam tentang penggunaan alat

pelindung diri pada tenaga kerja.

\section{DAFTAR PUSTAKA}

Anizar, 2009. Teknik keselamatan dan kesehatan Kerja di Industri. Yogyakarta: Graha IImu.

Ayyub, 2016. Tentang Hubungan Pengetahuan, Sikap, dan Tindakan Tenaga Kerja Dengan Pemakaian Alat Pelindung Diri (APD) di PT. Sermani Steel Corporation Makassar. Makassar : Program Diploma III Jurusan Kesehatan Lingkungan. Politeknik Kesehatan Makassar. (KTI tidak diterbitkan).

D.J. Heri. 2009. Promosi Kesehatan. Jakarta : EGC.

Daryanto, 2010. Keselamatan Kerja Peralatan Bengkel dan Perawatan Mesin. Bandung: Alfabeta.

DP, Ibrahim. 2009. Etika Profesi Lingkungan (sanitarian). Makassar: Poltekkess Jurkesling Press.

Hseptkreatifmantani, 2016. Standar alat pelindung diri. (Online) https://hseptkreatifmantani.wordpress.com/2016/01/19/standar-alat-pelindung-diri/.

Diakses ada tanggal 11 desember 2017.

Imran, Nurul. 2014. Tentang Studi Perilaku Alat Pelindung Diri Pada Ekerja Batu Nisan Di Desa Lempeang Kecamatan Tanete Riaja Kabupaten Barru. Makassar: Program Diploma III Jurusan Kesehatan Lingkungan. Politeknik Kesehatan Makassar. (KTI tidak diterbitkan).

Iskandar, Duddy. dkk. 2008. Jenis Jenis Alat Pelindung Diri (APD), (Online), http://duddyiskandar.blogspot.com/2008/12/jenis-jenis-alat-pelindung-diri-apd.html diakses pada tanggal 11 Desember 2017

Kholid, Ahmad. 2012. Promosi Kesehatan. Jakarta: Rajawali Pers.

Notoatmodjo, Soekidjo. 2007 . Promosi Kesehatan dan Ilmu Perilaku. Jakarta: Rineka Cipta.

Notoatmodjo, Soekidjo. 2010. Metode Penelitian Kesehatan. Jakarta: Rineka Cipta.

Nushana, Andi. 2017. Tentang Studi Perilaku Petugas Cleaning Servis Terhadap Penggunaan APD Dalam Menangani Limbah Padat (Sampah) Rumah Sakit Umum Syekh Yusuf. Makassar: Program Diploma III Jurusan Kesehataan Lingkungan. Politknik Kesehatan Makassar. (KTI tidak diterbitkan).

Rejeki, Sri. 2015. Sanitasi Hygiene dan K3. Bandung: Rekayasa Sains.

Sahani, Wahyuni, dkk. 2017. Buku Pedoman Karya Tulis IImiah. Prodi D-III. Makassar: Poltekkes Kesling Makassar.

Triwibowo, Cecep 2013. Kesehatan Lingkungan dan K3. Yogyakarta: Nuha Medika. ILO.

Wulansari, 2009. Pemakaian Alat Pelindung Diri Sebagai Upaya Dalam Pencegahan Kecelakaan Kerja Di Bagian Granule Di Pt. Bina Guna Kimia Ungaran, (online), https://eprints.uns.ac.id/.pdf diakses ada tanggal 11 Desember 2017

Yuli, 2017. BAB III ALAT PELINDUNG DIRI, (Online), http://www.academia.ed/BAB_III_Alat_Pelindung_Diri_APD_diakses pada tanggal 11 desember 2017

Zulkifli, 2013. Tentang Perilaku Terhadap Penggunaan Alat Pelindung Diri (APD) di Sermani Steel Makassar. Makassar: Program Diploma III Jurusan Kesehatan Lingkungan. Politeknik Kesehatan Makassar. (KTI tidak diterbitkan). 